\title{
Perangkat Lunak Koreksi Penggunaan Sumberkutipan Dan Daftar Pustaka Pada Jurnal Mahasiswa
}

\author{
Idrus Salim¹, Ari Muzakir ${ }^{2}$, Hadi Syaputra ${ }^{3}$ \\ ${ }^{1,2,3}$ Informatics Departement, Bina Darma University, Palembang, Indonesia \\ Email: 1idruska27@gmail.com, ${ }^{2}$ ariemuzakir@gmail.com, ${ }^{3}$ hadisyaputra@binadarma.ac.id
}

\begin{abstract}
Abstrak
Sumber kutipan dan daftar pustaka adalah suatu hal yang sangat penting dalam pembuatan jurnal tujuannya sebagai pengokohan argumentasi dalam sebuah karangan. Apalagi dalam penyusunan karya ilmiah, hal ini sebabkan adanya data dan informasi yang ada di dalamnya digunakan sebagai acuan untuk penelitian atau pengkajian selanjutnya bagi ilmuan lainnya. Hal itu tentu saja menimbulkan beberapa masalah seperti kesalahan pada sumber kutipan dan daftar pustaka yang tidak sinkron, control dan pengecekan sumber kutipan dan daftar pustaka yang baik dan benar jika dilakukan secara manual pasti akan menghabiskan banyak waktu. Untuk permasalahan itu munculah ide untuk membuat perangkat lunak koreksi sumber kutipan dan daftar pustaka pada jurnal. Metode yang digunakan untuk mengkoreksi kesalahan pada sumber kutipan dan daftra pustaka yaitu regular expression (REGEX), sebuah formula untuk pencarian pola suatu kaliamat/string dan sangatlah membantu dalam menemukan pola-pola kalimat. Dari hasil program tersebut system akan secara otomatis mengkoreksi sumber kutipan dan daftar pustaka pada jurnal sehingga dapat memudahkan editor dalam mengkoreksi, sehingga tidak terjadi lagi kesalahan pada sumber kutipan dan daftar pustaka pada jurnal.
\end{abstract}

Kata Kunci: Sumber Kutipan Dan Daftar Pustaka,Jurnal, Regular Expression

\section{PENDAHULUAN}

Dilembaga pendidikan tinggi memiliki tanggung jawab dalam mengembangkan Tridharma perguruan tinggi yang meliputi pendidikan, penelitian dan pengabdian pada masyarakat. Pengembangan tersebut dapat ditumbuhkan apabila didukung oleh suasana budaya akademik (academic culture) yang kuat dilembaga tersebut. Budaya akademik adalah suatu budaya yang tumbuh diperguruan tinggi yang mencerminkan sebuah suasana ilmiah dan ditandai oleh sejumlah aktivitas ilmiah melalui segenap kegiatannya, seperti aktivitas perkuliahan, seminar, kegiatan penelitian yang semua kegiatan tersebut disebarluaskan melalui publikasi ilmiah dalam bentuk jurnal. 
Penyebarluasan publikasi ilmiah melalui jurnal selain mengembangkan budaya akademik juga sekaligus menjadi ajang komunikasi akademik yang pada gilirannya memberikan kontribusi positif bagi perguruan tinggi dalam penyebarluasan ilmu pengetahuan melalui hasil-hasil penelitian yang telah dilakukan. Dengan penggunaan komputer dan internet yang saat ini semakin luas tersebut, memberikan lebih banyak kemudahan bagi mahasiswa dalam kegiatannya sehari-hari termasuk kegiatan yang melibatkan tulis menulis. Salah satunya yaitu pada bidang pendidikan. Banyak peneliti dikalangan mahasiswa, dosen, dan ilmuwan yang berlombalomba dalam menyumbangkan idenya untuk peningkatan pendidikan dan teknologi melalui penyusunan jurnal penelitian.

Jurnal penelitian umumnya berisi usulan solusi yang baru atau perbaikan dari solusi yang sudah ada terhadap suatu masalah, masalah yang sering terjadi didalam pembuatan jurnal sering terletak pada sumber kutipan dan daftar pustakanya. Kesalahan tersebut biasanya disebabkan oleh ketidak tahuan penulisan dalam mengambil sebuah sumber kutipan, kesalahan yang berhubungan erat dengan mahasiswa dalam membuat jurnal seringkali mengambil atau mengcopy paste dari sumber kutipan tersebut, akan tetapi daftar pustakanya tidak diikut disertakan dalam karya tulisnya, setiap jurnal yang masuk diwajibkan untuk melalui tahap pengkoreksian untuk mengecek apabila ada kekurangan dan kesalahan pada jurnal seperti adanya kesalahan sumber kutipan dan daftar pustaka atau informasi yang belum lengkap. Namun seperti manusia pada umumnya, kesalahan pada sumber kutipan dapat saja ditemukan lagi setelah tahap pengkoreksian dikarenakan editor kurang teliti dalam mengkoreksi.

Selain itu lebih berfokus pada kesalahan besar terkait isi jurnal sehingga proses deteksi kesalahan sumber kutipan dapat luput dari pengecekan. Padahal hal kecil seperti kesalahan dalam mengambil sumber kutipan dan daftar pustaka dapat berpengaruh terhadap informasi dan pengetahuan yang disajikan dalam jurnal. Kemudian waktu pengecekan dokumen yang terbatas dan banyaknya naskah jurnal yang masuk dengan jumlah halaman yang berbeda-beda memungkinkan kurang teliti dan cenderung tergesa-gesa dalam menganalisis jurnal. Kesalahan dalam mengambil sumber kutipan yang fatal dapat mengubah makna pengetahuan yang ingin disampaikan penulis dalam jurnalnya dan menimbulkan penyerapan informasi yang salah pada pembaca.

\section{METODOLOGI PENELITIAN}

Metode yang digunakan pada penelitian ini yaitu metode deskriptif. menurut sugiyono (2016, 2.1 h.207) metode deskriptif adalah metode 
yang dgunakan untuk menganalisis data dengan cara mendeskripsikan atau menggambarkan data yang telah berkumpul sebagaimana adanya tanpa bermaksud membuat kesimpulan yang berlaku untuk umum generalisasi.

\subsection{Metode Pengembangan Prototype}

Sebuah prototype adalah versi awal dari sistem perangkat lunak yang digunakan untuk mendemonstrasikan konsep-konsep, percobaan rancangan, dan menemukan lebih banyak masalah dan solusi yang memungkinkan (Dkk, 2015). Sistem prototype memperbolehkan pengguna untuk mengetahui bagaimana sistem berjalan dengan baik. Penggunaan metode prototyping di dalam penelitian ini bertujuan agar peneliti mendapatkan gambaran aplikasi yang akan dibangun melalui tahap pembangunan aplikasi prototype terlebih dahulu yang akan dievaluasi oleh user. Aplikasi prototype yang telah dievaluasi oleh user selanjutnya akan dijadikan acuan untuk membuat aplikasi yang dijadikan produk akhir sebagai output dari penelitian ini.

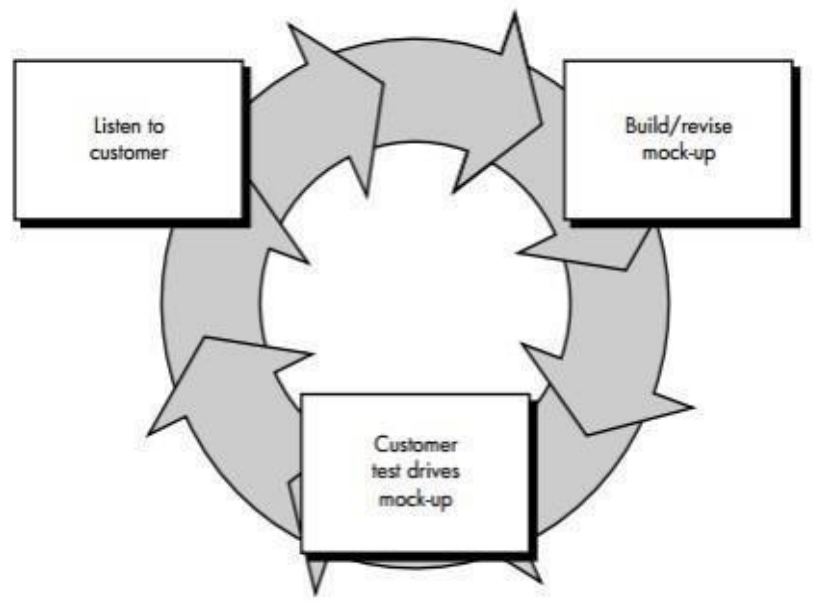

Gambar 1 Prototyping Model

Gambar 1 menjelaskan bahwa metode prototyping dimulai dengan mendengarkan kebutuhan dan masukan dari pengguna. Pengembang dan pengguna bertemu dan bersamasama menentukan tujuan keseluruhan untuk perangkat lunak dan mengidentifikasi apapun persyaratan yang diperlukan. Lalu pengembang membuat sebuah 
gambaran tentang aplikasi yang selanjutnya dapat dipresentasikan. Gambaran tersebut berfokus pada representasi aspek-aspek aplikasi yang akan terlihat oleh pelanggan/pengguna. Beberapa keunggulan dalam menggunakan metode prototyping.

1. Pengembang sistem dan pengguna saling berkomunikasi khususnya dalam hal penyamaan persepsi terhadap pemodelan sistem yang akan menjadi dasar pengembangan sistem operasionalnya,

2. Pelanggan/pengguna ikut terlibat secara aktif dan berpartisipasi dalam menentukan model sistem dan sistem operasionalnya sehingga pelanggan/pengguna akan puas karena sistem yang dibuat sesuai dengan keinginan dan harapannya,

3. Sistem yang dibangun memiliki kualitas yang diinginkan karena sesuai dengan kebang ada Butuhan.

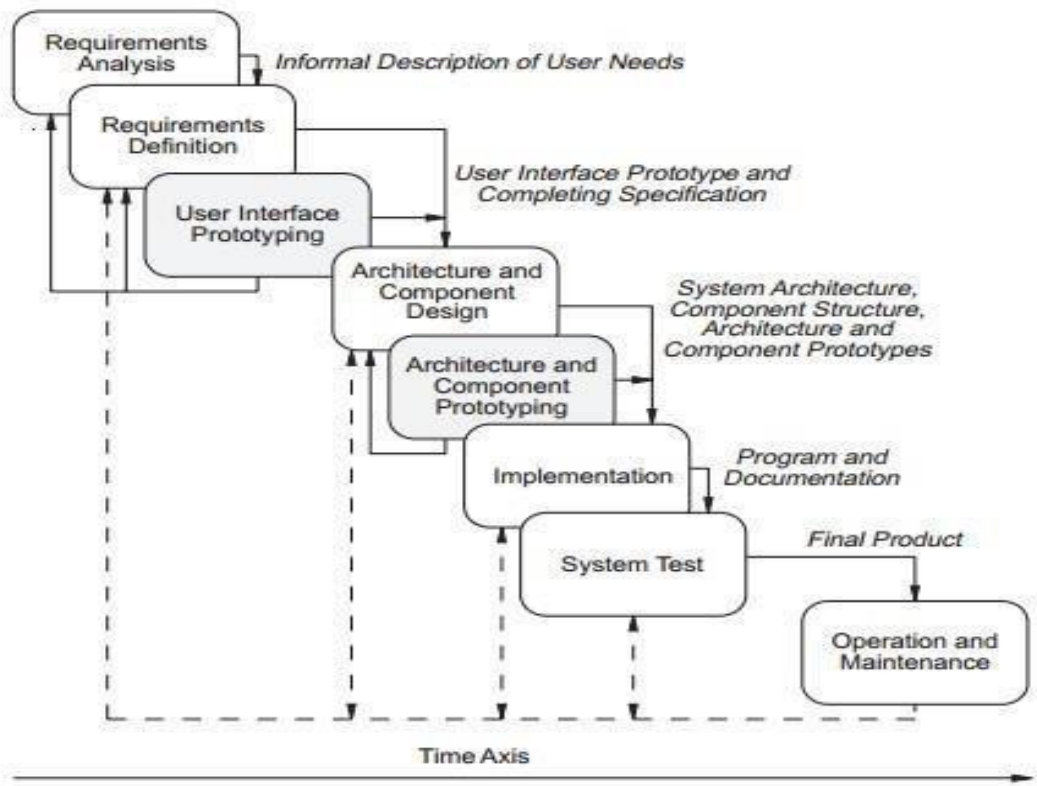

Gambar 2 Alur proses metode Prototyping

Gambar 2 menjelaskan mengenai alur pengembangan sistem dengan menggunakan metode Prototyping-Oriented Software. Pada tahap pertama, dilakukan analisis kebutuhan dan pendefinisian kebutuhan. Kebutuhan yang dimaksudkan disini adalah kebutuhan pelanggan/pengguna. Selanjutnya pada tahap kedua dilakukan 
pembuatan prototype dari aplikasi yang akan dibangun, mulai dari user interface prototyping dan dilanjutkan hingga penyusunan arsitektur dan komponen-komponen yang berkaitan dengan aplikasi yang akan dibangun. Selanjutnya dilakukan pengembangan sistem, dimana aplikasi akan dibangun sesuai dengan prototype yang telah dibuat sebelumnya, dan setelah aplikasi berhasil dibuat sesuai dengan kebutuhan maka dilakukan proses pengujian aplikasi sebelum aplikasi tersebut diimplementasikan.

\subsection{Regular Expression}

Menurut (Muliantara, 2009) Regular expression atau yang sering disebut sebagai Regex adalah sebuah formula untuk pencarian pola suatu kalimat/string. Sering kali orang beranggapan bahwa regex susah dan membingungkan. Namun sebenarnya regex sangatlah membantu dalam menemukan pola-pola kalimat. Sehingga percobaan terhadap semua kemungkinan pola kalimat tidak perlu dilakukan. Regular expression umumnya digunakan oleh banyak pengolah kata/text editor dan peralatan lainnya untuk mencari dan memanipulasi kalimat dengan berdasarkan kepada suatu pola tertentu. Banyak bahasa pemrograman yang mendukung regular expression seperti misalnya $P H P$, perl, VB dan Tcl. Sebuah alasan yang sangat bagus untuk menggunakan regexa adalah karena regex sangatlah powerfull. Pada level rendah regex dapat mencari sebuah penggalan kata. Pada level tinggi regex mampu melakukan kontrol terhadap data. Baik mencari, menghapus dan merubah. Mari kita pikirkan bagaimana cara untuk mencari sebuah file di hard disk.Seringkali digunakan karakter "?" dan "*”.Penggunaan karakter "?" mengandung arti bahwa sedang dicari sebuah sebuah file yang mengandung sebuah karakter tertentu dan karakter "**" mengandung arti sedang dicari nol atau lebih karakter.

\section{HASIL DAN PEMBAHASAN}

\subsection{Hasil}

Hasil dari penelitian ini adalah menghasilkan sebuah aplikasi berbasis dekstop yang dapat mempermudah prodi dalam mengkoreksi sumber kutipan dan daftar pustaka. Aplikasi ini dapat membantu program studi dalam mengkoreksi sumber kutipan dan daftar pustaka secara otomatis dan langsung 
mecari hasil dari kutipan dan daftar pustakanya. Editor dapat menginstall aplikasi ini pada komputernya dan melakukan pengecekan kutipan setiap jurnal dari isi jurnal, Jurnal yang telah dilakukan pengecekan nantinya jika sesuai dengan isi kutipan dan daftar pustaka maka akan dipublikasikan secara umum. Sehingga jurnal yang telah dipublikasikan tidak ada lagi kesalahan pada kutipan dan daftar pustaka. Aplikasi ini dibuat menggunakan bahasa visual C\# dan menggunakan regular expression dengan IDE visual studio 2017 serta menggunakan database MySQL. Pada pembahasan peneliti akan membahas mengenai user interface dari aplikasi koreksi sumber kutipan dan daftar pustaka pada jurnal mahasiswa berbasis dekstop yang akan menampilkan gambar dari aplikasi.

\section{1) Perangkat Lunak Koreksi Sumber Kutipan Dan Daftar Pustaka}

\section{A. Tampilan Awal Aplikasi}

Pada form input jurnal ini terdapat fitur browser, search, form isi jurnal, form gaya pustaka, dan form koreksi. Pada Tombol Browser berfungsi menampilkan form document yang terdapat pada komputer untuk mengambil jurnal yang tersimpan pada document komputer yang akan memulai proses koreksi pada aplikasi, yang nantinya akan menampilkan isi dari jurnal yang akan dikoreksi. Berikut adalah tampilan dari form input jurnal.

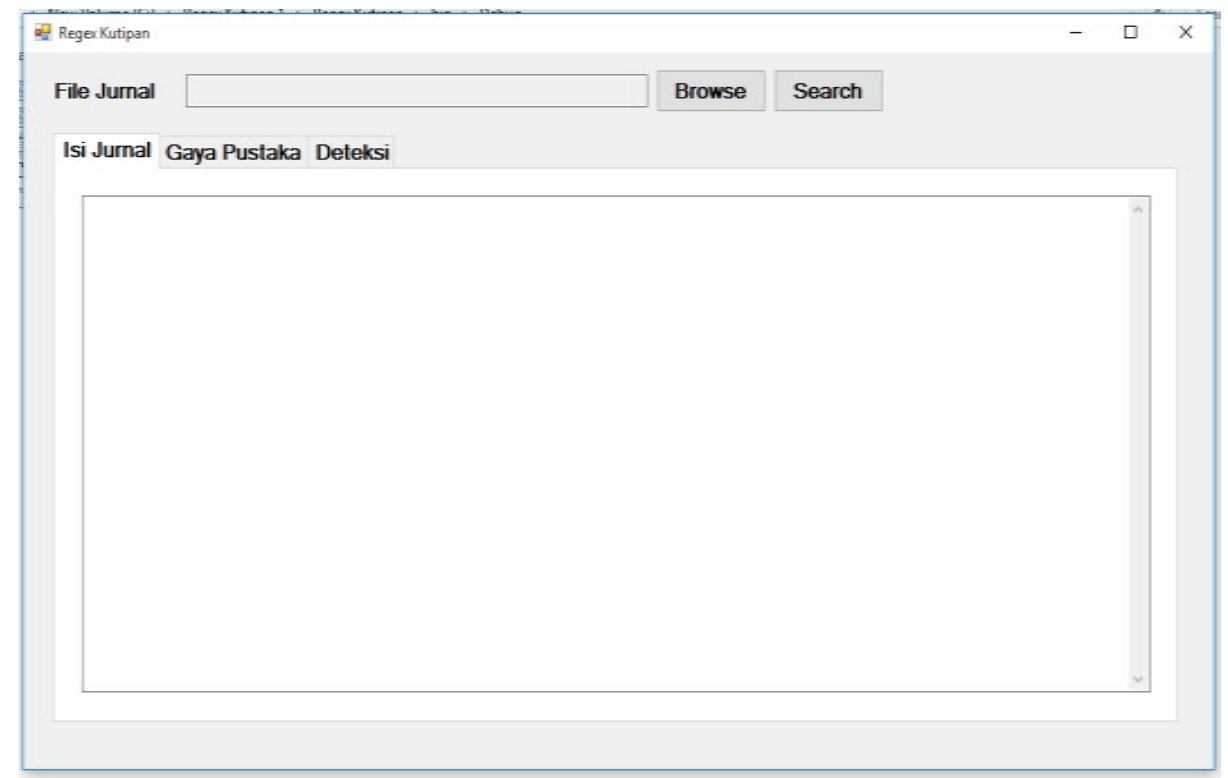

Gambar 3 tampilan pada form awal aplikasi 


\section{B) Tampilan Form Browser}

Pada browser dimana proses awal koreksi aplikasi untuk mengambil file jurnal yang telah disimpan pada dokumen komputer. Dan setelah file jurnal yang diambil dari dokumen kumputer maka aplikasi akan menampilkan isi dari jurnal tersebut.

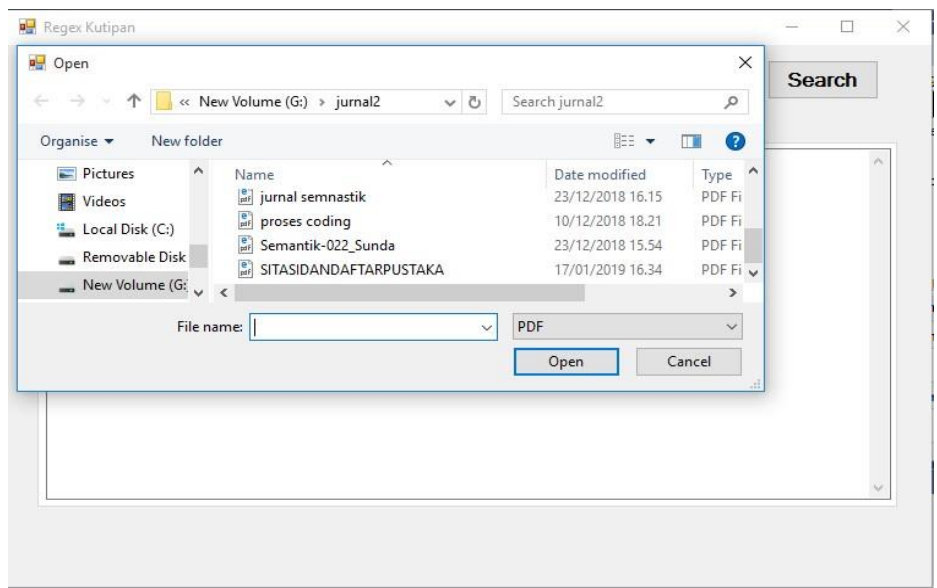

Gambar 4 tampilan pada browser

\section{C) Tampilan Form Isi Jurnal}

Pada form isi jurnal berfungsi menampilkan isi jurnal yang akan dikoreksi oleh aplikasi Sebelum aplikasi memulai proses koreksi editor dapat melihat isi jurnal yang akan di koreksi pada form isi jurnal.

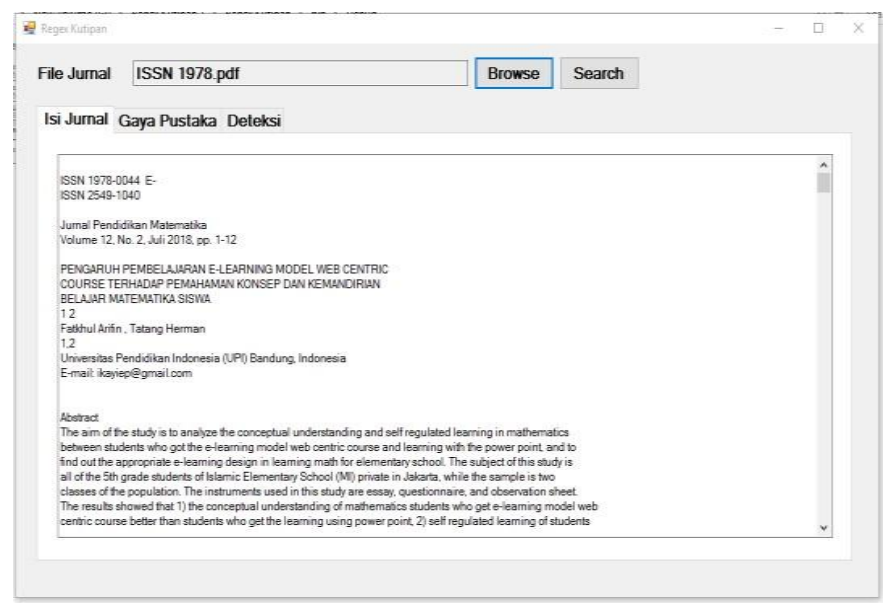

Gambar 5 tampilan pada form isi jurnal 


\section{D) Tampilan Form gaya pustaka}

Form gaya pustaka pada aplikasi akan menampilkan daftar pustaka dari jurnal yang di input serta menampilkan gaya pustaka yang digunakan pada jurnal tersebut dan dimana juga terdapat kesimpulan yang digunakan pada gaya pustaka serta mengatahui gaya terseut menggunakan satu gaya pustaka atau menggunakan beberapa gaya pustaka. Gaya pustaka yang dapat diproses meliputi IEEE, APA, dan harvard.

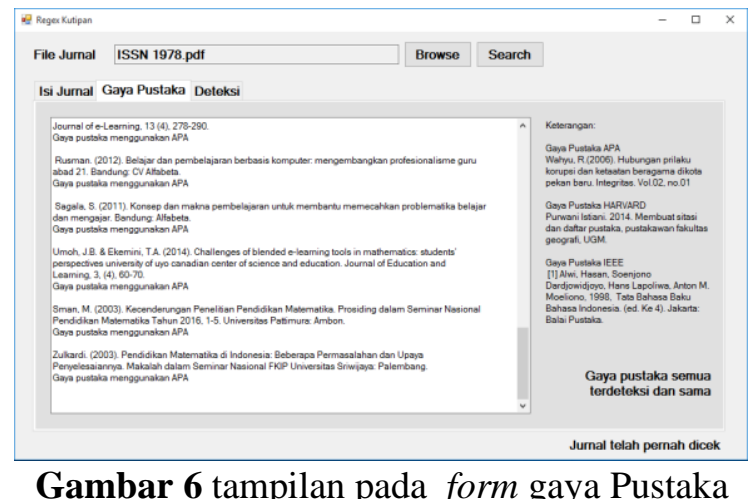

\section{E) Tampilan Form Deteksi}

Dari form deteksi pada aplikasi ini akan menampilkan hasil dari koreksi sumber kutipan dan daftar pustaka pada jurnal akan ditampilakan pada form deteksi, dimana form deteksi tersebut akan menampilkan hasil dari daftar pustaka dan sumber kutipan yang terdapat pada jurnal, serta form deteksi ini memberikan sebuah keterangan untuk daftar pustaka yang tidak memiliki sumber kutipan. Dan juga akan menampilkan hasil dari jumlah daftar pustaka dan sumber kutipan yang terdapat pada jurnal serta memberikan kesimpulan.

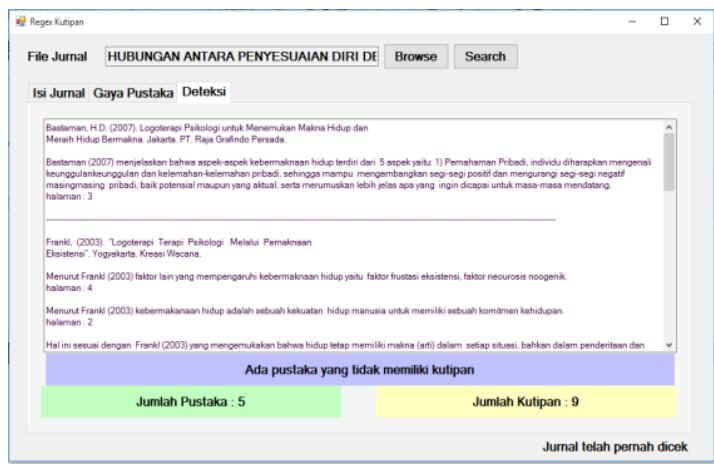

Gambar 7 tampilan pada form deteksi 


\section{KESIMPULAN}

Kesimpulan menggambarkan jawaban dari hipotesis dan/atau tujuan penelitian atau temuan ilmiah yang diperoleh. Kesimpulan bukan berisi perulangan dari hasil dan pembahasan, tetapi lebih kepada ringkasan hasil temuan seperti yang diharapkan di tujuan atau hipotesis. Bila perlu, di bagian akhir kesimpulan dapat juga dituliskan halhal yang akan/perlu dilakukan terkait dengan gagasan selanjutnya dari penelitian tersebut.

\section{DAFTAR PUSTAKA}

[1] W.-K. Chen, Linear Networks and Systems. Belmont, CA: Wadsworth, 1993, pp. 123-135.

[2] R. Hayes, G. Pisano, D. Upton, and S. Wheelwright, Operations, Strategy, and Technology: Pursuing the competitive edge. Hoboken, NJ: Wiley, 2005.

[3] The Oxford Dictionary of Computing, 5th ed. Oxford: Oxford University Press, 2003.

[4] A. Rezi and M. Allam, "Techniques in array processing by means of transformations, " in Control and Dynamic Systems, Vol. 69, Multidemsional Systems, C. T. Leondes, Ed. San Diego: Academic Press, 1995, pp. 133-180.

[5] O. B. R. Strimpel, "Computer graphics," in McGraw-Hill Encyclopedia of Science and Technology, 8th ed., Vol. 4. New York: McGraw-Hill, 1997, pp. 279-283.

[6] H. Ayasso and A. Mohammad-Djafari, "Joint NDT Image Restoration and

Segmentation Using Gauss-Markov- Potts Prior Models and Variational Bayesian Computation," IEEE Transactions on Image Processing, vol. 19, no. 9, pp. 2265-77, 2010.

[7] A. Altun, "Understanding hypertext in the context of reading on the web: Language learners' experience," Current Issues in Education, vol. 6 , no. 12 , July 2003. Available: http://cie.ed.asu.edu/volume6/number12 /

[8] H. Imron, R. R. Isnanto and E. D. Widianto, "Perancangan Sistem Kendali pada Alat Listrik Rumah Tangga Menggunakan Media Pesan Singkat (SMS)". Jurnal Teknologi dan Sistem Komputer, vol.4, no. 3, pp. 454-462, Agustus 2016.

[9] J. R. Beveridge and E. M. Riseman, "How easy is matching 2D line models using local search?" IEEE Transactions on Pattern Analysis and Machine Intelligence, vol. 19, pp. 564-579, June 1997. 
[10] E. H. Miller, "A note on reflector arrays," IEEE Transactions on Antennas and Propagation, to be published.

[11] L. Liu and H. Miao, "A specification based approach to testing polymorphic attributes," in Formal Methods and Software Engineering: Proc.of the 6th Int. Conf. on Formal Engineering Methods, ICFEM 2004, Seattle, WA, USA, November 8-12, 2004, J. Davies,

W. Schulte, M. Barnett, Eds. Berlin: Springer, 2004. pp. 306-19.

[12] J. Lach, "SBFS: Steganography based file system," in Proc. of the 2008 1st Int. Conf. on Information Technology, IT 2008, 19-21 May 2008, Gdansk, Poland [Online]. Available: IEEE Xplore, http://www.ieee.org. [Accessed: 10 Sept. 2010].

[13] H. A. Nimr, "Defuzzification of the outputs of fuzzy controllers," presented at 5th Int. Conf. on Fuzzy Systems, 1996, Cairo, Egypt. 1996. 